\title{
Politicidade do cuidado e processo de trabalho em saúde: conh ecer para cuidar melhor, cuidar para confrontar, cuidar para emancipar
}

\author{
Politicity of care and work process in health: \\ knowing to take a better care, taking care \\ to confront, taking care to emancipate
}

Maria Raquel Gomes Maia Pires 1

${ }^{1}$ Departamento de Serviço Social, Un iversid ade de Brasília.

Campus Un iversitário Darcy Ribei ro, ICC

Cen tro, Sobreloja Sl-432, Asa Norte, 70910-900

Brasília DF.

maiap@uol.com.br

\begin{abstract}
Politicity of ca re is about handling the disruptive of the relation between help and power for the construction of the autonomy of subjects. Such conception is expres sed mostly by the trihedron kn owing to take a better care, taking care to confront and taking care to emancipate, that, in social-historical specific con texts and adapted to the wo rking process in health, can constitu te a reorien ted referen ce of the domain relations. It is a theoretician-philosphical reflection, ba sed in a docto rate thesis, which deepens the ambiguity of the care, conceived such by the way of being solidary, such as by becoming to be political. This article aims to indicate the applicability of the politicity conception of the care in the scope of the health professionals working process, signaling emancipatories potentialities. The first part makes a deep reflection about the policity of caring in its ontological, social and political dimensions, arguing about the tense relation existing between help and power which is present in the gestu re of taking care. The second part co $n$ textualizes this theory in the unlike fo rm of organizing and producing health care, pre senting the discuss about the change of the attention model to the health. The third part is based in the emancipatory trihed ron of caring and points emancipatory indications to the working process of the professionals.
\end{abstract}

Key words Care, Emancipation, Power
Resumo Politicidade do cuidado diz respei to ao manejo disru ptivo da relação en tre ajuda e poder para construção da autonomia de sujeitos. Tal concepção se expressa principalmente pelo triedro conhecer para cuidar melhor, cuidar para confrontar, cuidar para emancipar, que, em con textos sócio-históri cos específicos e adaptado ao processo de trabalho em saúde, pode se constituir numa referência reordenadora de relações de domínio. Trata-se de uma reflexão teórico-filosófica, fundamentada em tese de doutorado, que aprofunda a ambivalência do cuidado, concebido tanto pelo modo de ser solidário, como pelo vir a ser político. Objetiva-se indicar aplicabilidades à concepção de politicidade do cuidado no âmbi to do processo de trabalho dos profissionais de saúde, sinalizando potencialidades emancipatórias. A primei ra parte faz uma reflexão aprofundada sobre a politicidade do cuidado nas dimensões ontológicas, epistemológicas, biológica e política, argumentando sobre a tensa relação entre ajuda e poder presente no gesto de cuidar. Na segunda, contextualiza-se essa teorização na forma desigual de organizar e produzir cuidados em saúde, discutindo-se a mudança do modelo de atenção à saúde. Na terceira, conclusiva, fundamenta-se o tried ro do cuidar e apontam-se indicações emancipatórias pa ra o processo de trabalho dos profissionais.

Palavras-chave Cuidado, Emancipação, Poder 


\section{Introdução}

A politicidade do cuidado reside na intrínseca a mbivalência da ajuda que, sen do poder, tanto domina como liberta fazeres humanos. A caracterís tica do cuidar, como gesto e atitude solidária, inclina-se para proteger e assegurar vida, direitos e cidadania. Porém, a relação fraterna aí impulsionada também é opressora e subjugante, utilizandose de artifícios calcados na solidari ed ade para manter-se em posição de domínio. Esta discussão integra a tese de doutorado Politicidade do cuidado como referência emancipatória para gestão de politicas de saúde: conhecer pa ra cuidar melhor, cuidar pa ra confrontar, cuidar para emancipar (Pires, 2004), defendida no programa de pós-graduação em Política Social da Universidade de Brasília, e discute teoricamente o caráter dinâmico, turbulen to, su bvers ivo, políticoe recon s trutivo do cuidar, a partir das seguintes questões: Como um cuidado eminentemente tutelar, que sobrevive da própria dependência, poderia desencadear ruptu ras emancipatórias a partir dessa mesma proteção? Poderia uma relação protetora vir a se constituir em impulso criativo à insubordinação autônoma? Existiria dinâmica subversiva na ajuda, típica relação de poder?

A politicidade do cuidado, con cebida na ambigüidade que a conforma, pode desconstruir assimetrias de poder a partir do triedro conhecer pa ra cuidar melhor, cuidar para confrontar, cuidar pa ra emancipar (uma produção pró pria que será aprofundada no decorrer de ste texto). Articulando saber, poder e ajuda, o referi do tried ro aprofunda as dimensões epistemológicas, ecológica, on tológica e social do cuidado, por meio da politicidade que lhe é intrínseca. Parte-se do supos to que o ato de conhecer, ou de computação/ cogitação (Morin, 1999), s en do político e biológi co (Ma tu rana \& Varela, 1997; Demo, 2002b), e en ten di do como forma natural de participar de um mundo social e historicamen te con form ado, instrumentaliza confron tos e autonomias libertárias. $\mathrm{O}$ tried ro emancipatório do cuidar, contextualizado na política pública e adapt ado ao proce sso de trabalho em saúde, pode secon stituir numa referência capaz de democratizar poderes por meio do fortalecimen to da autonomia de sujeitos. Este argumen to é aprofundado nas três partes que compõ em este artigo: a) politicidade do cuidado: cen tralidade do político para a gestão da ajuda-poder; b) politicidades na forma desigual de organizar e produzir saúde: entre o aprisionamento e a libertação do cuidar; c) tried ro emancipatório do cuidar e processo de trabalho em saúde: indicandodinâmicas disru ptivas. Preten de-se apontar possibilidades emancipatórias para o processo de trabalho dos profis si onais de saúde a partir da tese su pracitada (pesquisa teórica e prática, centrada no uso da politicidade do cuidado como referência teórico-analítica para a gestão de políticas de saúde, que investiga se a gestão de programas prioritários para o SUS, como o PSF, tem oportunizado cenários propícios à auton omia de sujeitos). Para os propósitos deste tex to, qual seja, indicar dinâmicas indutoras de reordenamen to de poderes para a prática dos profissionais de saúde, fundamentou-se principalmen te nas discussões que integram o referencial teórico e análise dos dados da referida produção (documen tos institucionais e trabalhos premiados na II mostra nacional de produção em saúde da família, ocorrida em julho de 2004).

\section{Politicidade do cuidado: cen tralidade do políti co para gestão da ajuda-poder}

A politicidade do cuidado pode ser en tendida como manejo político e reconstrutivo da relação dialética estabelecida entre ajuda e poder para a construção de autonomias de sujeitos, sejam estes gestores, técnicos, profissionais de saúde, usuários dos serviços de saúde, família, comunidade, enfim, cidadãos. Acerca da politicidade, adota-se a referência de Demo (2002a), que a con cebe como habilidade política humana de "saber pensar" e intervir criticamente, numa busca imanente por autonomia crescente. $\mathrm{O}$ en frentamen to dos limites postos, sejam sociais, econômicos, cultu rais ou biológicos, conforma o cen tro nevrálgico e motor da politici$\mathrm{d}$ ade humana. Para consolidar a idéia de pol iticidade como razão humana fundamental, o autor re sgata conhecimentos da biologia para argumentar sociologicamente. A partir do entendimen to biológico da intrínseca mutabilidade do ser vivo, con strói uma fundamentação teórica para o entendimento da politicidade com o possibilidade de construirmos uma socied ade menos desigual, mais ética e justa. Advém também desse autor uma referência import a n tesobre igualitarismo (possível pela democratização do poder) em oposição a igualdade (contraditó rio porque este mesmo poder, sendo estrutural, não desaparece facilmente). Na base 
desta discussão está a pulsação de uma pol iticidade biologicamente plantada, o que nos torna, a exemplo de outros seres vivos, (...) profundamente gregários e cooperativos, embora profundamentecompeti tivos (...) (2002a).

A partir do deb a te amplificado por Demo para explicar a politicidade, e se distanciando de qualquer fechamento determinista, é possível observar aspectos que sugerem uma interrelação dos fenômenos naturais, sociais e históricos pres en tes na realidade, quais sejam: 1) a politicidade, an tes de ser razão humana, la teja na matéria, estando presen te como dinâmica de reconstrução tanto nos processos vivos, como nas movimentações moleculares, atômicas e subatômicas que conformam os elementos não orgânicos da natureza; 2) os animais são seres políticos porque também se relacionam, in teragem, tensionam e transformam entre si, como se observa, por exemplo, nas formas de a s s ociação en tre seres vivos estu dadas pela bi ologia (cooperação, mutualismo, competição, simbiose, socied ade, en tre outros); 3 ) esta politicidade, no hom em, se complexifica, assumindo peculiaridades pró prias do ser dialético que sabe intervir pela recon s trução permanente; 4) tal intervenção humana, no capitalismo, tem intensificado a face agressiva e desigual das relações sociais, s en do nece s s á rio o re sga te da dim ensão ética dessa mesma politicidade, capaz de for jar processos emancipatórios.

Ainda sob as descobertas da biologia, na teoria da autopoiese, em Maturana \& Varela (1997), o dinamismo das transformações operadas pela dinâmica e diversidade da organização do ser vivo impressiona, a de spei to de certo fech a men to estrutural-funcionalista presente na con cepção de cla usura opera cional da máquina vivente. Segundo esta teoria, os process os produtivos e autônomos que con formam o ser vivo geram transformações dentro do sistema (máquina vivente), sendo o meio externo responsável apenas por perturbações menos expre s s ivas. A d a u su ra operaci onal atu a ria como uma rede fechada de relações e produções do sistema, limitando a mudança apenas ao interior da máquina vivente. Residiria aí a limitação dessa teori a uma vez que tais processos podem desencadear mudanças não apenas dentro, mas do sistema como um todo, numa perspectiva mais dialética. Apesar dessa ressalva, a centralidade da auton omia dos fen ô m enos bi ológicos, assumida pelos autores como traço primordial e ineren te à vida, traduz a vanguarda dessa teoria. O pulsar dos fenôm enos natu- rais, tão irreveren tem en te caracterizados tanto pela termodinâmica dos processos irreversíveis (movimento de turbulência e revolução presen te no aqu ecimen to das moléculas químicas que gera dissipações irrepetíveis, singulares e transform adoras na estrutu ra das mesmas), em Prigogine (1997), quan to pela autopoiese (a uton omia ou auto-eco-organização dos proce ssos vivos), em Ma tu rana \& Va rela (1997), consubstanciam um forte argumento em favor da politicidade.

O caráter disruptivo, autopoiético e irreversível in eren te aos seres vivos, concebido de maneira dialógica e dialética, fundamenta o argumen to da politicidade do cuidado. Nesta direção, a reconstrução da ajuda em prol da autonomia do outro, calcada em relações de poderes potencialmente subvers ivas, pode configurar um cuidar de cariz mais emancipatório. A a utonomia intrín seca dos sujei tos como potencial transformador, a historicidade e dinamicidade de umarea li d ade complexa e imprevisíved configuram a idéia da politicidade do cuidado como gestão intel igente da ajuda-poder. É prec isamente pela politicidade que o cuidado pode se tornar emancipatório ou desconstrutor das próprias estrutu ras que o subjugam. Trata-se de redimensionar o cuidado como possibilidade ética da humanidade, viabilizávd pela ambivalência intrínseca. Tal inten to sugere um movim en to dialético no qual a relação de dependência acontece mais para construir autonomia dos atores envolvidos, que para manter-se em si mesmo, como exercício autocen trado de poder. Ou seja, significa cuidar para que possamos ser capazes de reelaborar cada vez mais a tutela e exigir cidadania, on de o " $m e u$ " proj eto de auton omia só exis te como parte da auton omia co l etiva, saben do-a sempre rel a tiva.

O cuidado como gestão da ajuda-poder tem como fulcro central a dinamicidade tanto dos processos históricos, qua n to da natureza, a s sur mindo-se aqui uma abord a gem social, ecoló gica e ep is tem oló gica do cuidar (Pires, 2002). Por existir sobretudo na natureza, o cuidado faz parte da compleição dos seres vivos e da emergência dos processos cognitivos globais de uma mente incorporada, ocorrendo em múltiplas e diversas formatações. Sobre essa última expressão, explica-se: distanciando-se da clausura operacional que outrora assinalava, e articulando múltiplos saberes (psicologia cognitiva, fen omenologia e budismo), Va rela propõe que a refl exão precisa interrom per os padrões habituais de recorrência e programação, mantendo-se 
atenta e aberta. Aberta às possibilidades diferen tes daqu elas con tidas nas repre s entações comuns que as pessoas têm, a berta à vivência reflexiva prop i ci ada pela mente, a berta aos desígnios do caos e da incerteza, a berta às transformações advindas da dúvida e do acaso, a tenta às possibilidades emancipatórias que podem advir desse estado de ausência de fundamen to, con form an do o que ele denomina de en action. A ausência de um fundamen to essencial, de um comando único, de um self central e porto seguro das pulsões humanas, ao invés de ser considerado um aspecto negativo, é descri to como profundamente revel ador de condições libertárias, presente na existência co-dependente da própria vida. Por meio da enaction, os praticantes da aten ção/consciência podem aumentar a capacidade de se estar a tento às profundas experiências advindas da con exão entre corpo e men te.

Assim, s eja na turbulenta natu reza que bu sca su peração de equilíbrios pela irreversibilidade dos fen ôm enos (Pri gogine, 1997), na biologia dos processos autôn omos ou na experiência vuln erá velda refl lexão oriunda da junção do corpo com a mente, o cuidado, não sem conflito, in terage e tensiona seres por dinâmica interna, inerente ao pulsar da vida. É precisamente pelo conflito e incerteza presen tes no gesto de ajuda que ele pode vir a ser uma força revolucionária, traduzindo-se em politicidade su bvers iva. Com preen der o cuidado como vir a ser, contrário de ser, contemporiza-o como possibilidade de mudança ineren te às relações sociais. A liberdade manifesta na con cepção do vir a ser con stitui a potencialidade subvers iva do cuidado, expressa pela frivolidade, fugaci$\mathrm{d}$ ade e intrínseca transitoried ade do fenômeno do poder. $\mathrm{O}$ cuidado visto na totalidade envo 1 ve não só o modo de ser, estrutura mais definidora e capturável, como também o modo de vir a ser, característica que o torna dinâmico, perm e ado por volúpia e tensão dialética.

A este respeito, a discussão em Heidegger s obre o ser-no-mundo indui a dimensão da $c u$ ra/cuidado, que compõem a estrutura da presença (constituição ontológica de homem, ser humano e humanidade). É na pre-sença que o homem constrói seu modo de ser-no-mundo. Assim, segundo o filósofo da fen omenologia, o ser-no-mundo em sua essência é cura, en tendida como condição estrutural de existência humana. Ontologicamente, cura não pode significar uma atitude especial para con s i go mesmo, porque esta ati tu de já se caracteriza como pre- ceder a si mesma, envolvida por outros dois m om en tos estruturais, o já ser-em e o ser-junto do con ceito ôntico de cura também permite chamá-lo de cuidado e dedicação, integra ndo os comportamentos e atitudes humanas (Heidegger, 2002). Boff (1999), a poi a ndo-se em Heidegger, recon hece o cuidado como modo de ser essencial, como ethos humano e dimensão on tológica impossível de ser totalmen te desvirtuada. Defende que o cuidado entra na constituição da natureza e do ser humano, s em o qual não haveria a pró pria vida. Com o tom profundamente humano, filosóficoe teológi co, propõe uma ressignificação do cuidado, fundado numa nova ética do humano e na compaixão pela terra. A consistência teórica de Boff, a despeito de certa tendência esotérica tão po u co ambivalente, torna seu "saber cuidar" uma referência importante para as utopias humanas. Outro destaque oportuno é a crença de que o cuidado, em sentido irrestrito, reside na imanência da vida e do humano, admitin do-se aqui uma plenitude incapturável apenas pela razão.

Lon ge de se adentrar nesta seara filosófica, por fugir aos obj etivos des te tex to, cabe considerá-las referências importantes para o elem ento de ruptura presen te nas expressões do cuidar - imanen te em possibilidades, transcendente em desafios. Seja qual for a tendência pretendida, a capacid ade revo lucionária do cuidado ocorrerá menos pelo seu modo-de-ser que pelo seu modo-de-vir-a-ser. É principalmen te pelo que ainda não é, já sen do em si, que se pode argumentar em favor daemancipação. Ou, é precisamente pela dinâmica da liberdade, a proxima tiva de realizações e plena de desejos, que as utopias libertárias se realizam (Bauman, 2001). Ac reditar que as ações solidárias e reve stidas de autoridade, ou seja, fundadas em relações de poder próprias do sujeito que ajuda o o utro e define-se a si mesmo, podem prom over a utonomias capazes de vir a reordenar desigualdades, implica con ceber a centralidade do políticonas relações sociais estabel ecidas. É pela mediação de interesses, pela negociação árdua de projetos, pela intensidade da ágora pú$\mathrm{blico/privado} \mathrm{inerente} \mathrm{às} \mathrm{socied} \mathrm{ades} \mathrm{humanas}$ que as pretensas liberdades tomam con c retude. O cuidado como a juda que se reel a bora na relação de poder estabelecida, acon tece principalmente pela politicidade do cuidar, entendida tan to pelo seu modo de ser solidário, como pelo seu modo de vir a ser político.

O termo ajuda é discuti do por Gronem eyer (2000), que, ao tentar uma definição te ó rica de s- 
ta palavra para o Dicionário do De senvolvimento, apresenta-o como poder elegante. A autora argumenta que a ajuda ao des envolvimento, em especial aqu ela oferecida aos países do Terceiro Mundo, sempre se con stitu iu num mecanismo de dominação, em que a dissimulação e extrema discrição lhe foram sempre atributos principais. (...) O poder elegante jamais é identificado como poder. E ele é verdadeiramen te el egante quando, ca tivados pela ilusão de liberdade, os que a eles estão submetidos negam, repetidamente, sua existência. É uma forma de manter o cabresto na boca dos subordinados sem deixar que eles sintam o poder que está dirigindo. Em suma, o poder elega n te não força, não reco rre ao cacete nem às corren tes, simplesmente ajuda (...) (Gron em eyer, 2000). Como todo poder que se preza em manter-se forte, a ajuda a tua por mecanismos camuflatórios, lançandomão de apelos pretensamente morais para consolidar sua h egemonia. Afinal, quem ousa desconfiar daquele que estáajudando o outro? Tome-se o caso dos micropoderes presen tes no processo de trabalho em saúde. Como duvidar do médico, que além de deter o con hecim en to sobre o meu corpo e minha doença, prom ove o bem da $m i$ nha saúde a partir do seu saber-poder? (Foucault, 1979).

O cuidado, apesar de bem mais amplo por envo lver aspectos ontológicos, ecológicos, sociais, culturais e políti cos do ser vivo, tende a ser mais bem com preendido no campo da assistência à saúde, uma vez que as profissões têm progressivamen te disciplinado o cuidar em procedimentos, tarefas, tecnologias, rotinas e micropolíticas para cuidar das doenças (Merhy, 1997). Nesse caso, a ajuda como poder elegante a p arece em sua face mais velada, seja porque a en fermidade nos fragiliza diante da iminência da morte, seja porque a ajuda no campo da saúde historicamen te sem pre se aproximou do sacerdócio e da benevolência, legitimando hegemonias seculares que aprisionam corpo e subjetividade das pessoas à lógica da divisão social do trabalho em saúde (Rezende, 1989; Pires, 1989).

De volta à mac ropolítica, e na tentativa de arquitetar uma teoria de soberania para a nova forma gl obal de econ omia capitalista, Ha rdt \& Negri (2002) defendem que estaríamos vivendo num Império. O Império difere do imperialismo moderno que o antecede, principalmente, por não ter um centro único de poder definido, mas redes de poder que o sustentam. Por o utro lado, as forças criadoras da multidão que o amparam são capazes de construir um contra-império tipicamente revolucionário. O mecanismo de coerção utilizado opera no seio da vida social, atuando em malhas intrincadas, s en do disperso e pouco localizável. A discussão de biopoder em Foucault (1985) lança as bases da teoria do império, ou de como a gestão das forças do corpo foram, e conti nuam a ser, extremamente estra té gicas para a ac u mulação capitalista. A articulação en tre a reprodução humana e o capital, garantin do uma força produtiva dócil, foi o principal obj eto de intervenção do poder disciplinar do capitalismo industrial. A própria disciplina, tão formatada e institucionalizada na era moderna, é (re)discutida atualmente como uma introjeção ineren te à vida social.

O poder, situação estratégica complexa, permeada por disputa e sublevações num determinado contex to sócio-histórico, tan to em Foucault (1985) como em Hardt \& Negri (2002), en ca rrega-se mais da vida do que da ameaça da morte, dan do-lhe acesso direto ao corpo biológico arti c u ladointri n s ec a m en te com a história. Para Foucault (1985), é principalmente por meio desta biopolítica, que negocia domínios sobre a vida na história dos homens, que o saber- poder tem se constituído como um agente de transformação da vida humana. Para o autor, e referindo-se à história da sexualidadehumana, o mesmo interd i to que mantém o corpo disciplinado aos desígnios do capitalismo, submeti do às normas sociais que mantêm os corpos dóceis e hígidos para a reprodução do capital, pode se contra por a estes comandos por uma mesma bi opolítica interna, libertando-se da tutela por meio do cuidado de si, capaz de for jar auton omias. Nessa linha de pensamento, e acompanhando as tra $\mathrm{n}$ formações do capital, que hoje rom pe barrei ras físicas e territoriais, $\mathrm{o}$ poder igualmente se fragmentou nos corpos humanos, perden do em unidade definidora capturável, ganhan do em extensão irrepreen sível. Assim, a pesar da coerção externa, hoje as pessoas obedecem ou não mu i to mais por dinâmica interna, por uma biopolítica que lhe é intrínseca. É precisamen te sobre essa dimensão política da vida das pessoas que o poder imperial age, por mecanismos internos de con trole mediados pelo biopoder. Assim, ao contrário do que se poderia su por, vis toque no Império não ex is te uma sede específica de poder, a política não desaparece, mas sim sua soberba a utonomia. Em diálogo com esses autores, argumenta-se aqui por uma proposição disruptiva do cui- 
dar, por um cuidado que se recon s trua sempre para cuidar melhor, gerindo politicamente relações da ajuda-poder. Pa ra a área da saúde em especial, esse debate se insere na atual discussão sobre mudança do modelo assistencial em saúde, ou na busca de inovações e reconstruções do trabalho em saúde capazes de fortalecer a auton omia de sujeitos, sejam estes prof issionais ou usuários do sistema de saúde.

\section{Buscando politicidades na forma desigual de organizar e produzir saúde: entre o aprisionamen to e a libertação do cuidado}

A mudança do paradigma assistencial em saúde, uma das grandes lutas advindas do movim en to da Reforma Sanitária, permanece como utopia con cretizável. Tal ideário, fundado nos princípios doutrinários do SUS (universalidade, eqüidade e integralidade), sof re influência das profundas mudanças que vêm ocorrendo na economia e estrutura da sociedade (Offe, 1991; Santos, 1997), nos valores e hábitos de saúde da população (consumismo e medicalização dos problemas sociais, em que as questões de ordem pública, como saneamen to básico e água tratada, são tomadas restritamente a penas sob a ótica da dimensão privada, enfatizando-se o tratamento das enfermidades como fim em si (Fleury, 1997), além da própria formação e prática dos profissionais (tecnicista, cartesiana, positivista), inserindo-se, d a ro, no con tex to estrutu ral bem mais amplo de con formação das relações de ajuda-poder nas políticas sociais.

A referida mudança consistiria em transcen der a abord a gem cura tiva, hospitalocêntrica, fragmentada em especialidades, fundada em processos de trabalhos rigidamente divididos, alienados e na hegemonia do médico sobre a equipe de saúde (Campos, 1992; Pires, 1989). Em seu lugar, propõem-se abordagens interdisciplinares, com re sgate da integralidade da aten ção, centrada na saúde, na comunidade, no fortalecimen to das redes solidárias, na participação social e na pessoa como sujeito do seu processo de saúde - dœnça, seja em nível individual ou coletivo. Por modelo assistencial, en tenda-se a forma com que o cuidado em saúde é produ zi doe se or ganiza na polí tica de saúde para atender às necessidades da população. Apesar do uso bastante consagrado na litera tura de saúde, mantenha-se aqui uma ressalva crítica em relação à expressão modelo, por reduzir politicidades libertárias. Ou seja, m odelo pressupõe norma, padrão, rigidez e certo fechamen to epistemológi co, inibin do um diálogo mais aberto, dinâmicoe reconstrutivo com o utras formas de produzir e organizar cuidados em saúde, inscritas na diversid ade étnica e cultural das pessoas. Para o que vem se discorren do, es te termo se refere apenas a uma determinada forma de organizar o cuidado, em geral vinculada à política de saúde oficial, que por sua vez se insere no modo de produção capitalista. Não significa dizer que seja a única ou a mais importante maneira de cuidar, haja vista a diversidade de saberes, práticas e culturas que compõem a realidade em saúde do país (Weber, 1999).

O modelo assistencial, cura tivo e hospitalocêntri co envo lve a pesada indústria farmacêutica, de equipamen tos e insumos tecnológicos para o setor, gerando lu cros e acumulação do capital (mercado). Para a manutenção desta forma de produzir cuidados em saúde, que coin cide com a reprodução do sistema capitalista, es timula-se o con sumo de serviços e equ ipamentos em saúde, bem como a medicalização dos problemas sociais da população, que geram dividendos para o setor privado. Por outro lado, o merc ado de trabalho que se abre ao profissional de saúde exige justamente o que as universidades estão prontamente respon dendo, ou seja, um prof is si onal especializadoe tecnicamente competente, embora alienado de s eu processo de trabalho (cuidar) e politicamen te frágil (Pires, 2001). Para além de quaisquer interpretações mais duras sobre a determinação do econ ô mi co sobre o social, in compatível com a complexidade da realidade que se vem discutindo (Morin, 2002), é preciso pri orizar a tensa correlação de forças que se estabelece na con formação das políticas sociais, capaz tanto de dominação, qua $n$ to de sublevação emancipatória. A despeito disso, é inegável a influência do merc ado nas socied ades capitalistas, haja vista as extremas desigualdades sociais que se tem de en frentar em tem pos de globalização do capital.

Para a mudança pretendida conseguir ter êxito precisa mexer com o modo como vêm sendo produzidas as ações e serviços de saúde que, se historicamente vêm privil egian do o capital, urge volt ar-se para o trabalho. Nestesentido, a alienação do trabalho, ca tegoria marxista que busca apreender a acumulação do capital, figu ra como discussão rel evan te para en ten der 
como o cuidado à saúde, nas sociedades capitalistas, vem sen do organizado, produzido e acessado de manei ra desigual. Apesar de profundamente transform ado e contemporizado, o trabalho abstra to (Marx, 1963) segue como c a tegoria atual e rel evan te para as explicações e análises das políticas sociais capitalistas. Não se pretende, repita-se, limitar a tensa e complexa correlação de forças que se estabelece na conformação da realidade, entendendo-a histórico estrutural, uma vez que as estruturas se modificam na história (Minayo, 2001; Demo, 2002b). Afinal, a aposta num caminho único, seja fechado ou aberto, não tem dado conta das crises epistemológicas, sociais e econômicas pelas quais se tem passado, $n$ em tampouco dos dilemas é ticos da profunda desigualdade em que a humanidade se en contra (Boff, 2003; Dussel, 2002). Tal digressão seria incompatívd com uma tese cen trada na politicidade do cuidado, em que o cuidar, s en do relação que envolve ajuda e poder, está inscri to na subj etivid ade das pessoas, inseridas em con tex tos sócio-históri cos complexos.

O que se argumenta é que, apesar de algumas interpretações recoloca rem em debate a cen tralidade do trabalho para a reprodução do capital (Antunes, 2002), haja vista a transmutação e intensa flexibilização dos meios de produção, afirma-se que o trabalho perma nece ess encial para a acu mulação capitalista, em bora calcado muito mais na mais-valia relativa, centrada no conhecimen to, do que na mais-valia absoluta, calcada na força de trabalho humana. Se era assim no perí odo da revo lução industrial estudado por Marx, continua sendo, embora profundamente transmutado, no Império de Hart \& Negri (2002). Ainda sobre essa questão, e assumindo uma atualização polêmica do marxismo, Hollow ay (2003) aborda a alienação do trabalho sob o enfoque da transformação do poder-fazer em poder-sobre, defen den do que o capitalismo se baseia não na propriedade das pessoas, mas na propriedade do fato. O que Ma rx chama alienação, ou ruptura do hom em em relação ao seu obj eto de trabalho, Holloway denomina de separação do fato em relação ao fazer. O processo de trabalho é traduzi do como fluxo social do fazer, sendo este ineren te aos convívios humanos. A análise de Hollow ay (a despei to de não explicitar como seria possível mudar o mundo sem tomar o poder) consegue a profundar com pertinência o âmago da contradição capitalista, traduzido pelo aprisionamen to do fluxo social do fazer. Â medida que a alienação das relações sociais se aprofunda, subjetivizando cada vez mais a coisa e coisificando cada vez mais o sujeito, mais trági co se torna o dilema da mudança, que tende a se apre sentar con trad $\mathrm{i}$ toria men te como urgen te e inviável. Diante da iminência do impossível, surge a crítica ou o poder-para (conhecimento), o questionamento que tenta ir além da aparência, traçando as razões mais revel adoras do fenômeno criticado, que teria como obj etivo principal re sgatar a subjetividade dos sujeitos, recobra n do-lhe o que fora alien ado.

Di a $n$ tedo desafio da mudança med i ada pelo saber, faz-se necessário retornar à politicidade do cuidado, numa tentativa de antever indícios libertários. Cuidar é mais que ato mecanizado, rotinizado e alien ado de sentido, faz parte da atividade criativa dos seres, com pondolhe a estrutu ra de ser e vir a ser-no-mundo, sendo atitu de humana inscrita na esfera vital, su bjetiva e cultu ral das relações sociais. O fazer humano é permeado de cuidado, capaz tanto de oprimir, quan to de libertar. O que Holloway chama de submissão do poder-fazer ao podersob re, pode ser tradu zi do aqui como institucionalização do cuidado (Pires, 2002), significando o aprisionamento do cuidar em normas, rotinas e técnicas que desvirtuam o cuidado de sua existência criadora e reveladora (Heidegger, 2002). A institucionalização do cuidado, tenso em disputas entre o instituinte e o instituído, ou entre a ação dos sujeitos e a normalização, tende a pri orizar a tutela em detrimento da auton omia dos sujeitos, inserin do-se na lógica de abstração do trabalho em favor do capital. $\mathrm{O}$ cuidado institucionalizado, fragmentado e extorqu i do de subjetivid ades recon s trutivas, embora igualmente rico em politicidades subversivas, de certa forma vem sustentan do um modelo de atenção à saúde injus to e desigual, sob a forma da ajuda conformada em política de saú de tipicamen te capitalista.

Lon ge do ex tremismo recorren te em con siderar as políticas sociais ou como expedien te da acu mulação capitalista, ou como direi to redistributivo conquistado pelos trabalhadores (e distante também da bipolaridade simplista expressa na hipótese do engodo ou na hipótese da conquista denunciada por Coimbra (1987), na critica que faz às análises marxistas sobre a causação das políticas sociais na socied ade capitalista, apontando o simplismo, a-historicidade e compactação presen tes nas mesmas), cabe reafirmar que é na totalidade desses dois processos que as realidades sociais e econô $\mathrm{mi}$ cas se fundam. As políticas sociais sintetizam a 
contradição entre modo e relações de produção nas socied ades capitalistas, con formandose historicamen te a partir das correlações de forças estabel ecidas na arena política (Poulantzas, 1985; Offe, 1991; Faleiros, 2000). Porém, reparan do bem, pode-se dizer que, a despeito da ostensiva presença da socied ade civil na esfera pública de decisão em muitos contextos, a correlação de forças en tre mercado e bem-comum tem ocorrido com uma forte predominância do capital nas ações legitimadoras do interesse públ i co.

Falar em mudança do modelo assistencial pre s supõe alterar a excessiva tecnificação que o cuidado sofre no processo de trabalho dos profissionais em saúde, que, por sua vez, se insere nas correlações de forças que conformam as políticas sociais. Cuidar da saúde das pessoas, afinal, é mais que construir um obj eto e intervir tecnicamente sobre ele, é interagir, en contrar, alimentar a alma, considerar, reconstruirse, qu erer con struir proj etos (Ayres, 2001). Na relação estabelecida no ato de cuidar, em que a juda e poder se con frontam e se superam nas sínteses dos atos produzidos, ac redita-se que seja possívd emancipar por meio da construção de autonomias de sujeitos, saben do-as relativas e processuais. Pelo reconhecimen to de saberes como meio para forjar poderes adormecidos, ac reditando no fomen to de projetos capazes de restabelecer corpo e subjetividades pasteurizadas, e apostandono incapturável do viver humano, a ajuda pode emancipar-se da tutela, produzin do efei to de poder mais igualitário. Emancipar pela ajuda pode ser possível pelo tried ro emancipatório do cuidar - conhecer para cuidar melhor, cuidar pa ra confrontar, cuidar pa ra emancipar - no qual conhecimento, poder e auton omia se ten ci onam para libertar o fazer humano das amarras que o sucumbem, potencializando utopias con c retizáveis.

\section{Tried ro emancipatório do cuidar e processo de trabalho em saúde: indicando dinâmicas disruptivas}

A politicidade do cuidado está calcada na recon strução da autonomia de suj ei tos por meio da gestão da ajuda-poder. A defesa dessa concepção se fundamenta pelo que aqui se denomina tried ro emancipatório do cuidar: con hecer para cuidar melhor, cuidar pa ra confrontar, cuidar para emancipar (a escolha da metáfora do tri ed ro, mera men teilus trativa, foi inspirada no fato de essa figura geom é trica ser form ada con stitucionalmen te por três faces integradas, visualizadas em conjun to, geran do diversas imagens a depen der da posição e incidência do jogo de luz e sombras possíveis). Com tal proposição, argumenta-se em favor do conhecimento como forma natu ral de participar de um mundo socialmen tefundado em relações de ajudapoder. Articulando saber e poder, ou reconhecen do que o cuidado é também uma forma de conhecimento capaz de for jar possibilidades libertárias, pode-se ampliar a capacidade de confronto e reorden a mento das assimetrias de poder, emancipando por meio da mesma ajuda que domina e subjuga. Descon struir progressivamente relações de domínios por meio de ações solidárias implica um resga te crítico da discussão sobre conhecimento e poder, que s empre foi tensa e dialética. Sobre tal questão, Morin (1999) defen de a idéia de que o conhecimen to tem uma voc ação emancipatóri $a$, de modo que quanto mais se con h ece e se com preende, mais se é capaz de, reconhecen do os limites do verdadeiro, dedicar-se à sua procura e, por meio desse processo incessante de busca, emancipar-se relativamente de certas concepções. Dian te do desafio da complexidade do real, urge ao con hecim en to refl etir-se sobre si mesmo, situando-se e problematizan do-se no exercício proce s sual de aproximar-se darealidade.

Se tal conhecimen to pode ser visualizado como uma forma de participar da vida - e se o hom em é estruturalmente cuidado como modo de ser-no-mundo junto dos entes intramundanos (Heidegger, 2002; Boff, 1999) -, o ato de cuidar também pode ser con cebido como forma de conhecer e reinventar cotidianos. Pa ra se cuidar uns dos outros, numa propulsão tanto criativa quanto dominadora, incorpora-se, a preende-se e interpreta-se a realidade. Nesse espíri to ampliado, en tenda-se con hecim ento como dinâmica viva de produzir interpretações, significados, críticas e formas de participar da realidade. Con hecer é recons truir possibilidades de conviver, atuar e interagir com o planet a , con ceben do a disrupção, o con $\mathrm{f}$ ron to e a provisoriedade como cerne. É a manei ra como a natu reza se mantém divers a única e incapturável, reconduzindo tempos, espaços e histórias de forma não-linear e irredutível. Precisa-se, então, conhecer pa ra cuidar melhor, cuidar para confrontar, cuidar para emancipar, porque tal politicidade se ex pressa na intrín seca habilidade de cognição presen te na natureza, na cultura e na história da humanidade. 
Refletindo a humanidade da humanidade, Morin (2002) diz que a condição do sujeito é s eu egocentrismo, en tenden do-o dentro de princípios egoístas e altruístas ao mesmo tempo. Além do egocentrismo, considerado central, a subjetividade comporta a afetividade, pois o sujeito está também destinado potencialmente ao amor, à entrega, à amizade, à inveja, à ambição, ao ciúme, ao ódio e à relação com o outro, que se en contra no âmago do eu. Sendo, ao mesmo tempo, fechado e aberto, o egocen trismo do sujei to con cebe o outro como estranho e como parte, no sentido altruísta e egoísta pres en te na relação eu/outro e na conju gação do nós, seres humanos. Assim, o sujeito surge para o mundo na sua relação com o o utro, s em o qual o EU desapareceria. É na intersubjetivid ade que o sujeito se expressa e se define, por meio dela produz-se conivência, comunhão e possibilidade de compreensão. Ao mesmo tempo, a qualidade de sujei to, que garante autonomia do indivíduo, pode ser sub$m$ etida por essa mesma su bj etivi d ade, pelo mesmo âmago que lhe define como ser capaz de ação, produção, auto-eco-organização.

O ser humano é mimético, capaz de histeria, loucura e possessão. Mas também é único, compreensivo, generoso, almejante de paz e tranqüilidade. Essa turbulência hologramática contém um cosmo interi or e integra um cosmo superi or, origem da própria vida. Esse circuito a berto e intem pe s tivo traduz-se na idéia de homo sapiens-demens (Morin, 2002), capaz de razão e demência, linearidade e ambivalência que, de maneira antagônica e complementar, con forma os su j ei tos humanos. E s tes são sábi o s e loucos, a despeito das tentativas do paradigma moderno de planificá-los nos extremos da racionalidade(Bauman, 2001), como se ela não fizesse parte das pulsões e afetividades do homo-sapiens-demens. Para Morin, a afetividade medeia a relação en tre o homo sapiens e o homo demens, os componentes racionais e dementes do humano. Tal subjetividade se expressa nassen sibilidades poéticas, estéticas, míticas, religiosas e simbólicas. Exprime-se igualmente nos gestos de cuidado intersubjetivos que os compõem, na ajuda embebida de razão e emoção que tanto pode dignificar, quanto su bm eter o outro às suas ambições.

As pessoas são seres de cuidado e de destruição, de ajuda e de coerção, exprimem-se pela tensa disputa da loucura e sapiência que as en cerra. $\mathrm{O}$ ato de cuidar sof re pressões tanto da racionalidade empírica-prático-instrumen- tal, como das pulsões incontroláveis e delinqüen tes que integram o homo sapiens-demens. O cuidado é uma mediação cri adora en tre a racionalidade e a pulsão presente no afeto. Mis to de estratégia, ruptura e submissão, o cuidado transita entre a humanidade sapiens e demens, unindo-as numa propulsão reorganizadora de poderes conform ados. A politicidade do cuidado con templa o potencial da mudança, da de scon s trução recon s trutiva, da ru ptu ra dos interdi tos e sublevações opressivas, tendo por foco a construção da autonomia, síntese de diversos modos de cuidar. Trata-se de uma autonomia dependente (Morin, 2002), porque não existe autonomia viva que não seja depen dente (do meio, da auto - organização, da en ergia vital, da cultura, da história, da família, da sociedade, do Estado) ou polidependente. A liberdade do suj ei to aut ô nomo ocorreria numa situação qu e comporte, ao mesmo tempo, ordem e desordem, estabilidade e regularidade, certezas $a$ priori para que seja possível escolher e decidir num mínimo de desordem e risco. A autonomia do indivíduo humano se funda na qualidade de sujei to que se auto-afirma ocupandoo centro do seu mundo, mas que comporta um Nós (família, espécie, sociedade), uma inscrição comunitária (família, pátria), hereditária, histórica e cultural.

A politicidade do cuidado medeia o confronto das tensões en tre razão e demência presente nos sujeitos, podendo inaugurar novas ordenações de podere s. Trata-se de argumentar em prol de uma nova lógica do cuidar, em que se exercite uma ajuda que, sendo poder, tanto subjuga, como é capaz de libertar. Significa desenvo lver uma epistem ologia dialética do cuidado que ganhe em intensidade subversiva, mesmo sendo relação de dominação. O cuidado aqui propo s to con templa toda a ambigüidade e complexidade do sujeito discutida por Morin, fundamentando-se eticamen te na em ancipação dos sujeitos. A gestão da ajuda-poder para a emancipação de suj ei tos envo lve conhecer para cuidar melhor, cuidar para confrontar, cuidar para emancipar, pois precisa-se en tender mais profunda e dialeticamen te a realidade complexa para nela agir e cuidar, em nome de uma ética mais justa, cuidadora, igualitária e libertadora (Dussel, 2002). Ajudando para que os sujei tos conheçam melhor, unindo forma e con teúdo, quantidade e qualidade, razão e afeto, as chances e con quistas cidadãs podem ser alargadas. Tal intervenção cuidadora e subversiva pode fortalecer autonomias e qualificar 
enfrentamentos, emancipando pela desconstrução progressiva de assimetrias de poder.

$\mathrm{Na}$ tentativa de indicar dinâmicas disru ptivas para a forma desigual com que serviços e práticas de saúde vêm se organizando no contex to das políticas de saúde do Brasil, o cuidado precisa ser dinamizado como uma prática reconstrutiva da auton omia dos sujeitos, desde que se considere a conjuntura local/gl obal e as correlações de forças para qualquer pretensão de mudança que se queira. Há de se inaugurar n ovas formas de com preen der, in teragir e se relacionar com o outro (saben do-o parte de mim), de s envo lven do ações mais partilhadas de aju da e poder no campo da saúde. À luz desse debate, con si derem-se as premissas do quad ro 1 como referências cen trais para ori entar o processo de trabalho dos profis si onais de saúde, no âmbito do SUS.

As sumir a politicidade do cuidado como referência analítica e proposição indutora de mudança significa apostar numa ajuda que pri orize a libertação de fazeres, desconstruindo as amarras que o aprisionam e potencializando enfrentamen tos de situações opres s oras. Significa passar de técnico a agente públ i co de mudança, de administrador de decisões a formulador e indutor das mesmas, de paci ente a cidadão, de doente a pessoa humana, capaz tanto de sapiência criativa, qua n to demolição destruidora, mas na perfeita imperfeição que con forma o ser humano como vida.

\section{Quadro 1}

Tried ro emancipatório do cuidar e processo de trabalho em saúde : dinâmicas disru ptivas.

\begin{tabular}{|c|c|}
\hline Face mais visível do tried ro & Indicações emancipatórias \\
\hline $\begin{array}{l}\text { Conhecer para cuidar melhor } \\
\text { • com preen der o con tex to sócio-histórico } \\
\text { no qual são geradas as relações de ajuda-poder } \\
\text { na política de saúde, ampliandoos obj etos } \\
\text { de refl exão para além do en foque restri to } \\
\text { da doença. }\end{array}$ & $\begin{array}{l}\text { - refletir sobre a conjuntura capitalista em que as prá ticas e cuidado à saúde se } \\
\text { for jam, bem como a tensa disputa que se estabel ece entre o trabalho e o capital } \\
\text { no con texto das políticas sociais e, assim, com preender-se ator rel evante para } \\
\text { a reprodução e disrupção das condições indignas e aprisionadoras do seu } \\
\text { processo de trabalho; } \\
\text { - estudar a en fermidade para além do en foque dínicoe epidemiológi co, mas } \\
\text { como resultado da multidimensionalidade dos processos saúde - doença, pró prias } \\
\text { do uno/múltiplo humano; } \\
\text { - analisar o impacto das ações de saúde sobre a população para além da intenção } \\
\text { de perpetuar práticas e discursos, investiga ndo com perspicácia o impacto } \\
\text { que os saberes da comunidade poderiam ter sobre os processos de trabalho } \\
\text { dos profissionais de saúde; } \\
\text { - refletir sobre a vuln erabilidade do planeta e da necessidade inequ í voca de se } \\
\text { cuidar melhor da casa, do ethos (Boff, 1999) que acolhe a politicidade irreveren te } \\
\text { e transform adora da vida. }\end{array}$ \\
\hline $\begin{array}{l}\text { Cuidar pa ra confrontar } \\
\text { - fortalecim en to de auton omias indivi duais } \\
\text { e coletivas na equi pe de saúde e em sua relação } \\
\text { com o outro, coletivizan doconhecimen tos } \\
\text { capazes de democra tizar assimetrias de poder. }\end{array}$ & $\begin{array}{l}\text { - em vez de se utilizar redes de apoio e solidariedade como com pensação pela } \\
\text { omissão do Estado diante das políticas públicas, articulá-las aos movi m en tos } \\
\text { sociais e às lutas cotidianas por cidadania e renda; } \\
\text { - utilizar as manifestações do saber popular para mobilizar recu ros estratégi cos } \\
\text { da comunidade na (re) con strução dos suj ei tos de/ por direitos; } \\
\text { - modificar os modos de funcionar dos serviços de saúde partin do não somen te } \\
\text { das tecnoc racias profissionais, mas em diálogo partilh ado com as vivências } \\
\text { e con fron tos da população. }\end{array}$ \\
\hline $\begin{array}{l}\text { Cuidar pa ra emancipar } \\
\text { - gestão da ajuda-poder na micropolítica } \\
\text { do trabalho em saúde, inserida em con tex tos } \\
\text { sócio-históri cos ri cos em correlações de forças, } \\
\text { capazes de des con struir assimetrias de poder. }\end{array}$ & $\begin{array}{l}\text { - po tencializar e investir na forte penetração, estabelecimen to de vínculos e poder } \\
\text { de mobilização que caracteriza o processo de trabalho dos profissionais de saúde, } \\
\text { utilizando os como estratégias de mudança centrada no fomen to para } \\
\text { a utonomias dos sujeitos; } \\
\text { - ampliar en foques e abord a gens, respaldados em outros saberes, referências } \\
\text { técnicas e políticas setoriais, que otimizem a integralidade disru ptiva do cuidado } \\
\text { à saúde; } \\
\text { - ao invés de voluntarismo, ativismo político con scien te e democráti co. }\end{array}$ \\
\hline
\end{tabular}




\section{Referências bibliográficas}

An tunes R 2002. Adeus ao tra balho? Ensaio sob re as met amorfo ses e a cen tralidade do mundo do trabalho. 8a ed. Cortez, São Paulo.

Ayres JR 2001. Sujei to, intersubjetividade e práticas de saúde. Revista Ciência \& Saúde Col etiva 6(1):63-72.

Bauman Z 2001. Modernidade líquida. Jorge Zahar Editor, Rio de Ja n ei ro.

Boff 1999. Saber cuidar - Ética do humano. Vozes, Petrópolis.

Boff 2003. Ethos mundial - um consenso mínimo entre os humanos. Sextante, Rio de Ja n ei ro.

Campos GSW 1992. Reforma da reforma - repensando a saúde. Hucitec, São Paulo.

Coi m bra MA 1987. Será que o marxismo re s pon deà pergunta de como surgem as políticas sociais?, pp. 4465. In SH Abra n ches et al. Política social e combate à pobreza. Jor ge Zahar Editor, Rio de Janei ro

Demo P 2002a. Politicidade: razão humana. Ed. Papirus, Campinas.

Demo P 2002b. Complexidade e aprendizagem - a dinâmica não-linear do conhecimento. Ed. Atlas, São Paulo.

Demo P 2002c. Solidariedade como efei to de poder. Cortez-Insti tuto Paulo Freire, São Paulo. ( Coleção Perspectiva v. 6)

Dussel E 2002. Ética da libertação na idade da globalização e da exdusão. Vozes, Petrópolis.

Faleiros VP 2000. Política social do Estado capitalista. Cortez, São Paulo.

Fleury S (org.) 1997. Saúde e democracia - a luta do CEBES. Lemos Editorial, São Paulo.

Foucault M 1979. Microfísica do poder. Ed. Graal, Rio de Jan eiro.

Foucault M 1985. História da sexualidade I - A vontade de saber. 7a ed. (trad. Maria Thereza CA e JA Guilhon Albuquerque). Ed. Graal, Rio de Ja n ei ro.

Gronemeyer M 2000. Ajuda. In W Sachs. Dicionário do Desenvolvimento: Guia para o Conhecimento como Poder. Vozes, Petrópolis.

Hardt M \& Negri A 2002. Império. (4a ed.). Record. Rio de Jan ei ro-São Paulo.

Heidegger M 2002. Ser e tempo. Parte 1. (12a ed). Vozes, Petrópolis.

Holloway J 2003. Mudar o mundo sem tomar o poder. Viramundo, São Paulo.

Marx K 1963. O trabalho alienado, pp. 151-163. In Economia política e filosofia. (trad. Sílvia Patrícia). Melso, Rio de Ja n ei ro.

Maturana HR \& Va rela FJG 1997. De máquinas e seres vivos. Autopoiese: a organização do vivo. 3a ed. Artes Médicas, Porto $\mathrm{Al}$ egre.
Merhy EE 1997. SUS e um de seus dilemas: mudar a gestão e a lógica do processo de trabalho em saúde (um ensaio sobre a mac ropolítica do trabalho vivo), pp. 125-142. In S Fleury (org.). Saúde e democracia - A luta do CEBES. Lemos Editorial, São Paulo.

Min ayo MCS 2001. Estrutura e sujei to, determinismo e protagonismo histórico: uma refl exão sobre apráxis da saúde coletiva. Revista Ciência \& Saúde Coletiva 6(1):7-19.

Morin E 1999. Método 3 - O conhecimento do conhecimen to. Sulina, Porto Al egre.

Morin E 2002. Método 5 - A humanidade da humanidade Sulina, Porto Al egre.

Offe C 1991. Algumas contradições do Estado social moderno, pp. 113-131. In Trabalho e Soci edade: probl emas estru tu rais e perspectivas pa rao futu ro da sociedade do trabalho. Ed. Tempo Un iversitário, Rio de Jan ei ro.

Prigogine I \& Stengers I 1997. A nova aliança - a metamorfose daciência. Un B, Brasília.

Poulantzas N 1985. O Estado, o poder, o so cialismo. (Trad. Rita Lima). 2a ed. Ed. Graal, Rio de Janei ro

Pires D 1989. Hegemonia médica na saúde e na enfermagem. Cortez, São Paulo.

Pires MRGM 2001. Enfermei ro com qualidade formal e política: em busca de um novo perfil. Dissertação de mestrado. Universidade de Brasília, Departamento de Serviço Social.

Pires MRGM 2002. Con cepções de cuidado emancipatório: limites-possibilidades para as práticas profissi onais no con tex to das políticas de saúde do Brasil. Revista Ser Social 10:147-168.

Pires MRGM 2004. Politicidade do cuidado como referência emancipatória pa ra a gestão de políticas de saúde: conhecer para cuidar melhor, cuidar pa ra confrontar, cuidar para emancipar. Tese de do utorado. Univers i$\mathrm{d}$ ade deBrasília, Dep a rt a m en to de Serviço Social.

Re zende ALM 1989. Saúde: dialética do pensar e do fazer. Cortez, São Paulo.

Sa n tos BS 1997. Pela mão de Alice-o so cial e o político na pós-modernidade. 2a ed. Cortez, São Paulo.

Va rela FJ et al. 2003. A men te incorpo rada - ciências cogni tivas e experiência humana. Artmed, Porto Al egre.

Weber BT 1999. As artes de cuidar: medicina, religião, ma gia e positivismo na República rio-granden se - 18891928. UFSM, Santa Maria. EDUSC, Bauru.

Artigo apresentado em 25/10/2004

Aprovado em 12/01/2005

Versão final apresentada em 23/03/2005 